\title{
Quantification of coronary enhancement - reproducibility of methods and feasibility of quantification in health and disease
} \author{
Valentina O Puntmann ${ }^{1}$ \\ From 16th Annual SCMR Scientific Sessions \\ San Francisco, CA, USA. 31 January - 3 February 2013
}

Niharika Varma ${ }^{*}$, Rene M Botnar ${ }^{2}$, Andreas Indermuehle², Sarah A Peel ${ }^{2}$, Gerald F Greil ${ }^{1}$, Eike Nagel ${ }^{1}$,

\section{Background}

Coronary enhancement (CE) imaging by magnetic resonance (MR) is a novel, non-invasive approach for visualization of contrast uptake within the coronary artery vessel wall. Quantification of CE may help to individualize subpopulations at risk for the benefit of early risk assessment and intervention. Here we sought to compare the reproducibility of several quantification methods and to investigate the feasibility to detect differences in healthy subjects and disease.

\section{Methods}

All imaging was performed with a 3T MRI scanner. Targeted volume coronary imaging was performed using double-oblique imaging planes parallel to either the left and right coronary artery defined by a 3-point plan-scan tool. A balanced steady state free precession sequence (acquired in-plane resolution $=1.25 \times 1.25 \times 3 \mathrm{~mm}$; TR/TE/ FA: $4.2 \mathrm{~ms} / 1.5 \mathrm{~ms} / 110^{\circ}$ ) was used for visualization of the lumen. Subsequently, inversion-recovery T1 weighted 3D gradient echo coronary imaging (TR/TE/FA: 6.1msec/1.9 $\mathrm{msec} / 30^{\circ}$ ) was performed 40 minutes after administration of $0.2 \mathrm{mmol} / \mathrm{kg}$ of gadobutrol. Three methods of quantification M1-M3, were applied to the proximal coronary artery of each subject's dataset. M1 and M2 generated a mean contrast to noise ratio (CNR) by using coronary and aortic blood signal intensity (SI): M1 only included the visually detectable enhancement in the wall of each arterial segment whereas M2 included the complete segment (lumen and wall) and derived an average SI per segment (Figure 1). M3 was used to quantify a 'total visually

'Cardiovascular Imaging, King's College London, London, UK

Full list of author information is available at the end of the article detectable area' of CE. Analysis was performed by two independent observers for inter and intra-observer reproducibility. We then tested the feasibility of these methods to generate values in healthy subjects and those with either coronary or systemic inflammatory disease.

\section{Results}

Analysis could be performed in 100 and $93 \%$ of thirty subjects for M1-2 and M3, respectively. M1 and M3 both showed reasonable overall intraobserver agreement (M1: $\mathrm{r}=0.91 ; \mathrm{P}<0.01$, mean difference $(\mathrm{MD}) \pm \mathrm{SD}=-0.04 \pm 1.1 ; \mathrm{M} 3$ : $\mathrm{r}=0.89, \mathrm{P}<0.01, \mathrm{MD} \pm \mathrm{SD}=-0.2 \pm 0.4)$. Between observers, $\mathrm{M} 1$ and $\mathrm{M} 3$ showed good reproducibility $(\mathrm{M} 1: \mathrm{r}=0.88, \mathrm{P}<0.01$; $\mathrm{M} 3: \mathrm{MD} \pm \mathrm{SD}=0.5 \pm 2.8 \mathrm{r}=0.75, \mathrm{MD} \pm \mathrm{SD}=2.1 \pm 1.4, \mathrm{P}<0.01)$. Method M2 showed inferior intra and inter-observer agreement. Using M1 and M3, there was a significant difference between healthy subjects $(n=7), \operatorname{CAD}(n=10)$ and SLE $(\mathrm{n}=13)$ patients, respectively (M1, CNR (mean \pm SD) $1.9 \pm 0.8$ vs. $5.4 \pm 1.9$ vs. $6.4 \pm 1.3$, one-way ANOVA: $\mathrm{P}<0.01$; $\mathrm{M} 3, \mathrm{~mm} 2: 1.03 \pm 0.9$ vs. $3.8 \pm 2.2$ vs. $3.2 \pm 1.4, \mathrm{P}=0.002$. Using $\mathrm{M} 2$, no distinction between healthy subjects and patients could be made $(\mathrm{p}=0.2)$.

\section{Conclusions}

Quantification of visualized CE in proximal coronary segments using CNR and total area is feasible and reproducible. Both methods are able to discern significant differences between health and disease.

\section{Funding}

NIHR Biomedical Research Centre award (Atherosclerosis theme). 

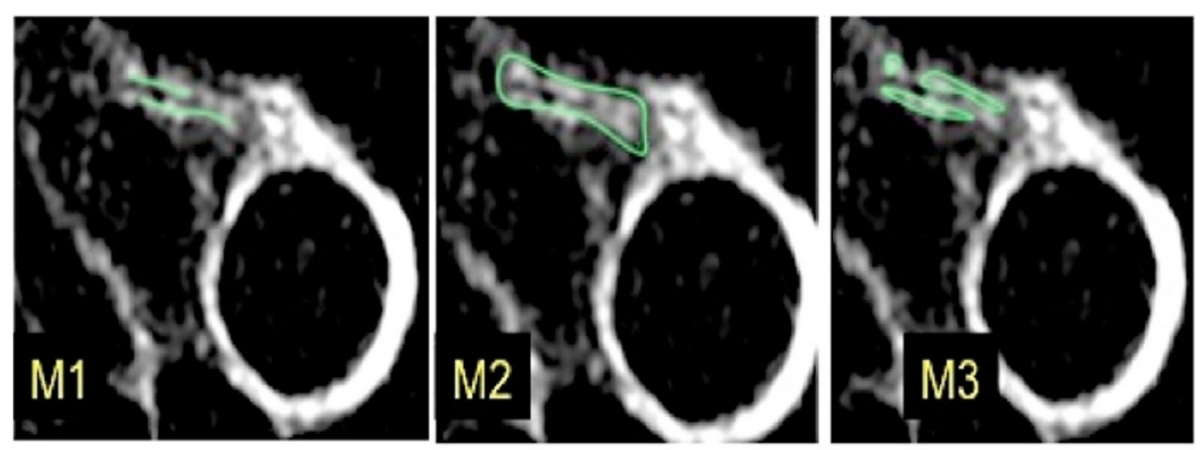

\section{C.N.R $=$ Total (mean) SI vessel wall-SI Aorta} Standard Deviation (Noise)

Total area method

Figure 1

\section{Author details}

${ }^{1}$ Cardiovascular Imaging, King's College London, London, UK. ²Department

of Medical Physics and Bioengineering, Division of Imaging Sciences and

Biomedical Engineering, King's College London, London, UK.

Published: 30 January 2013

doi:10.1186/1532-429X-15-S1-P84

Cite this article as: Varma et al:: Quantification of coronary

enhancement - reproducibility of methods and feasibility of

quantification in health and disease. Journal of Cardiovascular Magnetic

Resonance 2013 15(Suppl 1):P84.

Submit your next manuscript to BioMed Central and take full advantage of:

- Convenient online submission

- Thorough peer review

- No space constraints or color figure charges

- Immediate publication on acceptance

- Inclusion in PubMed, CAS, Scopus and Google Scholar

- Research which is freely available for redistribution 